\title{
The Impact of E-Learning in Teaching Arabic Language for Non-Native Speakers
}

\author{
Elsayed Mohamed Salem Salem Elawadi, Zulazhan Ab. Halim, Najeeb Abbas Al-Sammarraie, \\ Yousef Abubaker El-Ebiary, Bishwajeet Pandey
}

\begin{abstract}
The effect of E-learning and computer software program utilization in the Arabic language teaching among non-native speakers on the students' achievement in the Malaysian context, was examined in this study. The Malaysian Government's interest towards Arabic language teaching and learning among the non-native Malaysian speakers, has increased the progress of this teaching. Meanwhile, technological advancements have obliged teachers to employ computer multimedia in reaching some key parameters within the process of education. Challenges that teachers face in information delivery are explored in this study. The application of multimedia in teaching has facilitated teachers in the course outline preparation. Further, technology application in numerous life scopes, teaching included, is essential, especially in Arabic language teaching, specifically for non-native speakers. In achieving the sought after results, inductive analytical approach was used in this study. Considering the nonstop technology development, all the technological aspects of the Malaysian language centers were exploited, especially on the optimal application of present-day E-learning methods. Lastly, several recommendations to expand this technology for easy teaching and learning process were presented in this study.
\end{abstract}

Keywords: E-learning, Computer assisted language learning, Teaching languages for non-native speakers.

\section{INTRODUCTION}

In Malaysia, Arabic language teaching is still progressing. Notably, in this country, there is association between Arabic Language Teaching and learning and religious sciences. The present study therefore supports the necessity to apply the educational methods across the teaching and learning process within the classroom. This is especially relevant in the modern technology in language teaching via mobile devices equipped with apps and multimedia. It is hence important to persuade those in education field to employ these wide-ranging modern educational methods, to the level that it increases the significance of Arabic language teaching that it

Revised Version Manuscript Received on July 10, 2019.

Elsayed Mohamed Salem Salem Elawadi, Assoc. Prof. Dr., Faculty of Languages and Communication, UniSZA University, Malaysia.(email: sayedsalim@unisza.edu.my)

Zulazhan Ab. Halim, Assoc. Prof. Dr., and Dean Faculty of Languages and Communication, UniSZA University, Malaysia. (email:zulazhan@unisza.edu.my)

Najeeb Abbas Al-Sammarraie, Assoc. Prof. Dr., Faculty of Computer and Information Technology, MEDIU, Malaysia. (email:dr.najeeb@mediu.edu.my)

Yousef Abubaker El-Ebiary' Assoc. Prof. Dr., Faculty of Informatics and Computing, UniSZA University, Malaysia. (email:yousefelebiary@unisza.edu.my)

Bishwajeet Pandey, (email: gyancity@gyancity.com) becomes comparable with other subjects (e.g., English language, Mathematics, Science, etc.). This would increase the interest of students in cross educational stages.

The descriptive and analytical approach was employed in this study. In the process, scientific articles, documents, as well as books were referred in the expansion and scientific comparison of ideas and thoughts presented by educators and experts in regards to mobile apps and multimedia application for educational purposes.

\section{STATEMENT OF THE PROBLEM}

The 21 st century is marked by information reform and the scientific challenges, which have led to the extensive trend of computers application in all life aspects of people, including the aspect of education. Consequently, knowledge economy is currently the objective that the world is trying to achieve. Meanwhile, in the arena of education, the development of computer assisted language learning instructional mobile apps with the application of multimedia techniques requires a massive investment. For this reason, the effectiveness of mobile apps on the learners' performance is worthy of the scrutiny.

\section{METHODOLOGY}

As previously mentioned, the descriptive and analytical approach was the chosen approach in this study. Accordingly, scientific articles, documents, as well as books were referred in the expansion and empirical comparison of ideas and thoughts presented by experts and educators concerning mobile apps and multimedia application for educational purposes.

\section{AIMS OF THE STUDY}

The present study attempts to develop an instructional program to teaching Arabic grammar which includes the passive voice. Additionally, this study attempts to ascertain the impact of the program on the achievement of students in the language.

\section{STUDY CONTRIBUTION AND IMPORTANCE}

In the Malaysian context, learning mobile apps are still barely explored. So far, researches covering mobile-based 
instruction in this country are still too few. Nonetheless, the mobile apps utilization in Arabic language teaching, particularly the teaching of Arabic grammar, in the context of Malaysian learners has been examined by a few in the past. This study will explore the advantages of computer application in language learning on the whole, specifically in Arabic language learning. Also, the present study attempts to address the gap that exists between the theoretical and practical facets of mobile apps utilization in language teaching. As such, the findings of this study may be of value for different classes of individuals.

\section{LIMITATIONS OF THE STUDY}

The present study is limited to the AL Madinah International University (MEDIU) students of first year in Malaysia. These students were from the faculty of languages, foundation Arabic language, and MEDIU language center for academic year 2017/2018.

\section{REVIEW OF RELATED LITERATURES}

Operating on mobile devices, for instance, tablet computers and smart phones, mobile application refers to a software application. For these devices, nearly all can be purchased already equipped with a number of apps put together as pre-installed software. Among these apps include calendar, web browser, email client, mapping program, in addition to an app that can be employed in the purchase of music or other media or more apps [1].

Multimedia encompasses a content which utilizes a blend of diverse content forms for instance text, video, audio, animations, images, and interactive content. Relevantly, the terms media and multimedia are distinct from one another, in a sense that media employ merely basic computer displays including text-only or traditional forms of material that are printed or manually produced. Contrariwise, multimedia are recordable, playable and displayable, and with the use of information content processing devices, user can interact with multimedia or gain access to the information. In this regard, computerized and electronic devices are among the devices used in multimedia. Besides that, multimedia can be employed in a live performance as well [2].

Equally, multimedia devices encompass devices of electronic media that are utilized in the storage and experience of multimedia content. In the context of fine art, multimedia and mixed media are distinct from one another in a sense that multimedia have bigger scope (e.g., inclusion of audio). Meanwhile, the term that often refers to interactive multimedia is "rich media." Additionally, hypermedia expand amount of media content within the application of multimedia [3].

In the context of Arab Organization for Education, the concept of multimedia encompasses the incorporation of several elements in teaching, these include the use of slides, print, audio and video recordings, movies, and so forth [4]. As such, multi-media educational relationship involves the integration of its elements [5].

Information can be dispersed in different ways, such as through words (oral form) and images (visual forms). In the use of multimedia, all these (among others) can be integrated, as multimedia combine high quality image, audio, video, painting, and so forth, together with the presence of interactive environment [6].

Certain applications of computer software employ biblical texts, audio (e.g., music songs), images (e.g., pictures, graphics, and maps), movement (e.g., cartoon images, animated text, and animation) and videos, at different times. Such applications need computer software with multimedia processors as these processors provide fast processing and high storage [7], [8].

From the definitions above, it appears that there are some elements of multimedia involved. These include the presence of a double integrated elements, elements any combination of these elements and their compatibility and compatibility and integration between the preceding elements such as the union between sound and image [9].

Modern computers generally have the capacity to display colors, audio, video and motion. Hence, via the incorporation of these specific capacities, computers can operate the multimedia. Computers are thus a good and influential tool in the operation of multimedia. Notably in the multimedia operation, elements of submission or presentation and response or reaction are present [10].

Pertinently, in the context of this study, the notion of multiple teaching and learning media encompasses all computer programs that handle the educational material and learning, whereby educational materials are presented in the form of video and audio, video, text and movement, within a fusion between these elements and their integration, for the purpose of enhancing the process of teaching and learning. It is therefore appropriate to deduce that computers have the capacity in generating and also operating the multimedia [11].

\section{ANALYSIS AND RESULTS}

Multimedia elements in mobile apps include text, image and graphic, movement, sound and video. Each is elaborated as follows:

Text entails educational material that is to be displayed to the learner in print form. The utilization of educational text or PRA is necessary because the text provides clarification on the material, and for some students, they need to see the information in writing. In the use of text, user needs to consider the appropriate content, lines and colors. Further, text can be displayed in many ways such as lists, as background, or in the animated form, and so forth. All these will increase the attention of students towards the text. However, the utilization of $100 \%$ text in teaching is not desirable and other elements such as sound, image, animation etc. should also be incorporated in order to increase the effectiveness of teaching and learning.

Images and graphic in multimedia involves the capacity in displaying charts and maps. This element also involve the ability in handling still images and photographs as well. Images are input to the computer either animated take them from a digital example, scanner, or is it develop by using the various drawing programs camera and vary these programs in the way they work and production drawings.

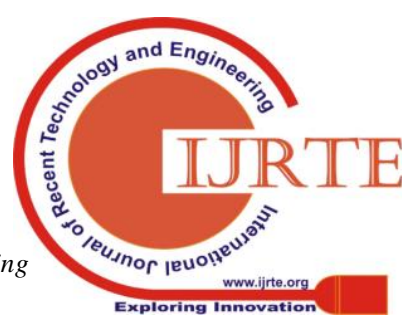


Movement in multimedia relates to text and image elements. In this context, movement needs to be expressive. Notably, animated images are better as they appear more attractive compared to still ones. Movement increases the attractiveness the image and generates excitement to learner. It also makes learning more interactive.

Sound element in multimedia involves the conversion of sounds into digital signals which can be included into any computer software. For instance, user can use computer to play the Quran recitations, or place sound effects to images. Sounds can also be used as input information, as in voice recognition, which allows user to talk instead of keying in instruction to the computer.

Video element is important element in multimedia, aside from denoting movement and central credibility. Furthermore, in the process of integrating all elements (i.e., text, image, movement, and sound), the technology advancement has assisted user in the use of video to the computer, resulting in the use of more effective media in the process of in teaching and learning.

Multimedia utilization allows teacher to express any information in countless of ways. Not only that, considering the multiple representations of the information, the use of multimedia stimulates many senses of learner and cater to different orientations of learner. Hence, effective learning can be achieved. As such, multimedia is characterized by the capacity of information transfer with the application of diverse means for the purpose of presenting the information in the most appropriate forms, while also imparting learners with the freedoms in handling educational material, allowing interaction between user and the material, which leads to the optimal and interesting learning. Meanwhile, teacher plays the role of coordinator in the multimedia usage.

In the domain of education and training, there are 3 common concepts as follows: Hypertext, Hypermedia and Multimedia. In specific, multimedia denotes diverse procedures of tools, materials, and means for information display. Furthermore, the utilization of computer through this sense interferes in the sense the term Hypertext and Hypermedia.

A number of computer programs are being applied in the education field. In this regard, Word processing programs, databases creation, programs for statistical processing and presentation are among the vital ones.

Considering their significant contribution in providing multimedia in teaching and learning process, the presentation programs or application software becomes the focal point of this study. Using a presentation program, learning materials can be displayed on the learner's mobile phone. Accordingly, in this field, the most important computer characteristic is the ability to synchronize the elements of colors and images with the text display, resulting in the appropriate setting for the teaching and learning process. This capacity is particularly crucial in when three-dimensional drawings are used.

In this technology age marked by technical knowledge and cultural explosion, the computer is highly integral. In fact, the use of computer is highly influential and crucial, and is widespread in all life spheres, particularly in teaching and learning context. Furthermore, considering that the primary objective of education is to achieve continuous improvement for students in mastering certain skills aside from accomplishing the educational goals, keeping pace with the technological development becomes a necessity.

Computers can quickly and accurately carry out the mathematical and logical processes, and systematically analyses the storage and retrieval of information. In the context of modern teaching, these computer capacities are highly beneficial, as teacher could effectively teach using the computer in manipulating the teaching materials. As computers are fast and accurate, aside from having the ability to display information in various manners, teaching using computers is flexible. Here, information can be displayed through books and audio-visual aids. In view of the major successes achieved by the computer in the field of education, and the most important characteristics of successful penetration of this research effective uses in the field of education.

Computer is regarded as a multi-purpose educational device (among many others). In the process of education, this is highly crucial, as such device brings a lot of advantages. Owing to its multiple features, computer has gained a significant place in the field of education, across multiple and accumulated experience, resulting from the actual application him in various fields of education and learning processes, and most important of these features:

With the use of computer, information can be both stored and retrieved quickly, while data bank can easily configured. Additionally, computer can be used in teaching hard skills which is highly time consuming to master. Hence, the use of computer allows sufficient time and opportunity for education and training. Besides that, it can speed up the completion of tasks, while also reducing performance errors. Furthermore, with opportunities for discrete instruction, the use of computer increases the capability in controlling the process of education. As the use of computer facilitates teaching, teacher would have more opportunity to cater to the needs of each student, by providing guidance to the learning process and addressing individual problems.

Computer usage increases students' activity. Not only that, it also impact learning speed. With the use of computer, students can have access to learning items which are attractively displayed with the application of certain programs including aligned context of the Legends multiple distinct methods of display. The effectiveness of computer utilization in the education field owing to its features has been proven. Accordingly, the use of Mobile Application facilitates the accomplishment of educational goals, and mobile app usage in the processes of teaching and learning furnishes roughly $40-60 \%$ of the allocated education to master the current conventional methods time. The application is also accessible anywhere and at any time.

The use of mobile applications in the teaching and learning allows creative and positive interaction and this improves the learning progress of students. The application also allows instantaneous feedback, as opposed to the traditional classroom situation. Further, the use of computer allows the recording and monitoring of learner responses and reactions. It also allows mutual interaction between learner
Blue Eyes Intelligence Engineering 
and the apps. Additionally, the self-confidence of learner in terms of linguistic and technical ability is increased with the use of the computer. The computer also allows learner to control his/her learning phase in the program. Learner and computer can easily and positively interact and this facilitates learner's completion of study, and ultimately, this leads to the achievement of the anticipated educational goals.

\section{RESULTS}

In this study, the concept of multimedia in teaching and learning relates to computer programs which address the educational material and learning, which allow the presentation of educational material in the format of video and audio, video, text and movement, in integrated form, for the purpose of achieving improved teaching and learning process. In multimedia, the elements are text, images, sound, movement, and video, and multimedia effect to be employed in today's education domain to foster better learning in various ways.

Notably, a strong link was found between education and multi-media, and the use of computer in terms of the effectiveness of use, and flexibility in running the program. Also, in this day and age, multimedia is appropriate for teaching and learning. In fostering education with the use of multimedia, many methods and theories need to be considered, to assure success in the teaching and learning process. Accordingly, procedures need to be consistently followed in the use of Mobile application for educational purposes. The special educational model is also considered in the application.

\section{SUGGESTIONS AND RECOMMENDATIONS}

The abovementioned findings have led to the following recommendations:

The impact of the use of computerized programs in teaching Arabic language grammar on the achievement of students should be examined in future studies.

Issues of grammar achievement in other regions in Malaysia in gaining better understanding of the impact of mobile apps on Arabic teaching need to be explored further.

The effectiveness of language teaching with the utilization of application software needs further scrutiny. The effectiveness of standard methods utilization on the teaching of language skills and other language components needs to be explored further as well.

Varying the teaching methods and techniques would be of value to teachers because this allows them to cater to the specific needs as well as interests of students. Computerized method should also be used more frequently and more intensively.

Teachers need to be equipped with the skills in Leader of Education Model with the application of technology in the classroom. They therefore need to be trained for the purpose

Teachers need to be trained in order to develop their technical abilities in the use of multimedia in teaching.

Taking care of using multimedia technology and follow up on all new and used in all detective school because of its effect on the achievement, direction and operations of different thinking.

\section{REFERENCES:}

1. Ehlers, U. D. (2014). Quality in e-learning from a learner's perspective.European Journal of Open, Distance and E-learning, 7(1).

2. Ezeah, C. (2014). Analysis of Factors Affecting Learner Participation in Asynchronous Online Discussion Forum in Higher Education Institutions.Journal of Research and Method in Education, 4(5), 8-14.

3. Farooq, M. S. (2016). Perceptions of prospective teachers about factors influencing classroom management. Journal of Quality and Technology Management, 7(1), 23-38.

4. Ghazinoory, S., \& Afshari-Mofrad, M. (2016). Ranking different factors which affect E-Learning outcomes. International Journal of Computer Theory and Engineering, 4(2), 234.

5. Hansen, D. J. (2003). Book review: E-learning: Strategies for delivering knowledge in the digital age (Author: M. Rosenberg). Educational Technology \& Society, 6(3), 80-81.

6. Noesgaard, S. S., \&rngreen, R. (2015). The effectiveness of e-learning: An explorative and integrative review of the definitions, methodologies and factors that promote e-Learning effectiveness. Electronic Journal of E-Learning, 13(4), 278-290.

7. Sun, P. C., Tsai, R. J., Finger, G., Chen, Y. Y., \& Yeh, D (2016). What drives a successful e-Learning? An empirical investigation of the critical factors influencing learner satisfaction. Computers \& education, 50(4), 1183-1202.

8. Tsinidou, M., Gerogiannis, V., \& Fitsilis, P. (2010). Evaluation of the factors that determine quality in higher education: an empirical study. Quality Assurance in Education, 18(3), 227-244.

9. Van der Vleuten, C. P. M., \& Driessen, E. W. (2014) What would happen to education if we take education evidence seriously?. Perspectives on medical education, 3(3), 222-232.

10. Yassin, M. Y. A. (2018). Electronic Enterprise Future for IT and Business Environments. International Journal on Contemporary Computer Research (IJCCR), 2(1), 1-7.

11. El-Ebiary, Y. A. B., Al-Sammarraie, N. A., Al Moaiad, Y., \&Alzubi, M. M. S. (2016, October). The impact of Management Information System in educational organizations processes. In e-Learning, e-Management and e-Services (IC3e), 2016 IEEE Conference on (pp. 166-169).IEEE. 